
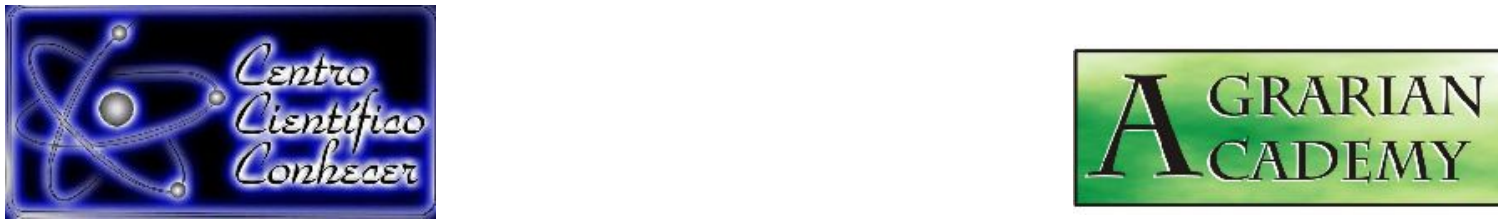

\title{
ADAPTABILIDADE DE GENÓTIPOS DE FEIJÃO VULGAR NO PLANALTO DE LICHINGA, MOÇAMBIQUE
}

\footnotetext{
Adélio Zeca Mussalama ${ }^{1}$, Argentina Rodrigues V. Forma ${ }^{2}$, Castro Joaquim Roque $^{3}$, Caetano Miguel Lemos Serrote ${ }^{4}$

${ }^{1}$ Engenheiro Agrônomo pela Universidade Eduardo Mondlane, Moçambique. Mestre e Doutorando em Fitossanidade na Universidade de Pelotas (UFPel. Docente da Universidade Lúrio (UniLúrio), Moçambique.

${ }^{2}$ Engenheira em Desenvolvimento Rural pela Universidade Lúrio (UniLúrio), Moçambique.

${ }^{3}$ Engenheiro Agrônomo pela Universidade Católica de Moçambique (UCM). Investigador Estagiário do Instituto de Investigação Agrária de Moçambique (IIAM) - Centro Zonal Noroeste (CZNw), Moçambique.

${ }^{4}$ Engenheiro Florestal pela Universidade Eduardo Mondlane (UEM), Moçambique. Mestre e Doutorando em Engenharia Florestal na Federal de Santa Maria (UFSM). Docente da Universidade Lúrio (UniLúrio), Moçambique. serrotec@yahoo.com.br
}

Recebido em: 15/12/2021 - Aprovado em: 15/12/2021 - Publicado em: 30/12/2021 DOI: 10.18677/Agrarian_Academy_2021B2

\section{RESUMO}

No presente estudo foi avaliado o desempenho de genótipos de feijão vulgar (Phaseolus vulgaris) no planalto de Lichinga, Moçambique. Foram testados 14 genótipos de feijão vulgar e uma variedade local usando o delineamento em blocos completos casualisados com 4 repetições. Foram estimados parâmetros de crescimento e de rendimento sendo os dados submetidos a análise de variância e teste de Tukey a $5 \%$ de probabilidade. Não houve diferença significativa para a maioria dos parâmetros avaliados: número de plantas emergidas, ataque de doenças, número de vagens por planta, número de sementes/vagem, peso de vagens e produtividade. O genótipo DAB449 destacou-se em termos de altura de plantas, enquanto a variedade local e os genótipos SCM32, DAB433, NAE13, NAE87 e ALB1 obtiveram os maiores comprimentos de vagem, e o genótipo BF13607-9 levou menos dias para florir. Os genótipos ALB117, NAE13 e NAE87 tiveram os maiores pesos de 100 sementes. Assim, o genótipo BF13607-9 destacou-se nos parâmetros de crescimento e o genótipo NAE87 foi destaque nos parâmetros de rendimento.

PALAVRAS-CHAVE: Crescimento, Rendimento, Phaseolus vulgaris. 


\title{
ADAPTABILITY OF COMMON BEAN GENOTYPES IN THE LICHINGA PLATEAU, MOZAMBIQUE
}

\begin{abstract}
In this study, we analyzed the performance of common bean genotypes (Phaseolus vulgaris) in the Lichinga plateau, Mozambique. We tested 14 common bean genotypes and a local variety using a randomized complete block design with 4 replications. Growth and yield parameters were estimated and the data were submitted to analysis of variance and Tukey's test at $5 \%$ probability. There was no significant difference for most parameters evaluated: number of emerged plants, disease attack, number of pods per plant, number of seeds per pod, pods weight and productivity. The DAB449 genotype stood out among others in terms of plant height, while the local variety and the SCM32, DAB433, NAE13, NAE87 and ALB1 genotypes had the longest pods, and the BF13607-9 genotype took less days to flower. The ALB117, NAE13 and NAE87 genotypes had the highest 100-seed weights. Thus, the BF13607-9 genotype stood out in the growth parameters and the NAE87 genotype stood out in the yield parameters.
\end{abstract}

KEYWORDS: Growth, Yield, Phaseolus vulgaris.

\section{INTRODUÇÃO}

De origem mesoamericana e andina, o feijão vulgar (Phaseolus vulgaris) é uma das espécies agrícolas mais antigas do mundo. Trata-se de uma planta herbácea, trepadeira ou rasteira, levemente pubescente. Desde sua domesticação até a atualidade, passou a ser a base da alimentação humana em vários países, majoritariamente em vias de desenvolvimento, sendo considerada a segunda fonte de proteína na África Oriental e a quarta na América tropical (GOUVEIA, 2011). Os sete maiores países produtores de feijões secos em 2016 foram: Myanmar $(5.189,977$ t), Índia $(3.897,611$ t), Brasil $(2.615,832$ t), Estados Unidos $(1.269,916 \mathrm{t})$, Tanzânia $(1.158,039 \mathrm{t})$, China $(1.127,127 \mathrm{t})$ e México $(1.088,410 \mathrm{t})$, tendo sido responsáveis por $58 \%$ da produção mundial (SILVA et al., 2018).

A produção de feijão vulgar em Moçambique vem aumentando em função da necessidade cada vez mais crescente de alimentação para a população. A área de produção está estimada em 89,9 ha, estando a província de Tete com a maior área $(29,92$ ha), seguida de Niassa (28,57 ha) e Zambézia (12,41 ha) (INE, 2011).

A maior parte da produção moçambicana é exercida pelo setor familiar, caracterizada por baixos rendimentos em função da tecnologia rudimentar usada, ocorrência de pragas e doenças e uso de variedades locais de baixa produtividade (CIPRIANO; SILVA, 2017). Os rendimentos obtidos no país para a cultura do feijão vulgar situam-se na ordem dos $0,75 \mathrm{t} / \mathrm{ha}$, considerado baixo tendo em conta as potencialidades agro-ecológicas desta região (JOCHUA et al., 2003).

Desse modo, torna-se importante a realização de pesquisas em diversos locais do país visando ao desenvolvimento de variedades mais produtivas. No 
presente estudo foi avaliado o comportamento de 15 genótipos de feijão vulgar, provenientes do programa de melhoramento do Centro Internacional de Agricultura Tropical (CIAT), visando obter os que melhor se adaptam às condições da agroecológicas do planalto de Lichinga.

\section{Área de estudo}

\section{MATERIAL E MÉTODOS}

O experimento foi desenvolvido na Estação Agrária de Lichinga (EAL), localizada a $4,5 \mathrm{~km}$ da Cidade de Lichinga (Figura 1). O clima da região abrange as zonas planálticas e montanhosas de Lichinga, com precipitações médias mensais de 118,4 milímetros $(\mathrm{mm})$. A temperatura média anual é de $18,6{ }^{\circ} \mathrm{C}$. As deficiências hídricas são geralmente baixas (um a três meses) e a evapotranspiração potencial é igual ou inferior a $1300 \mathrm{~mm}$. É caracterizada pela ocorrência de solos argilosos vermelhos (Rhodic Ferralsols ou Ferralíticos) das zonas planálticas embora possam ainda aparecer associados a solos ferralíticos de cores alaranjada, amarelada e acinzentada dependendo da sua posição no terreno (INE, 2013).

FIGURA 1 - Localização geográfica da área de estudo.

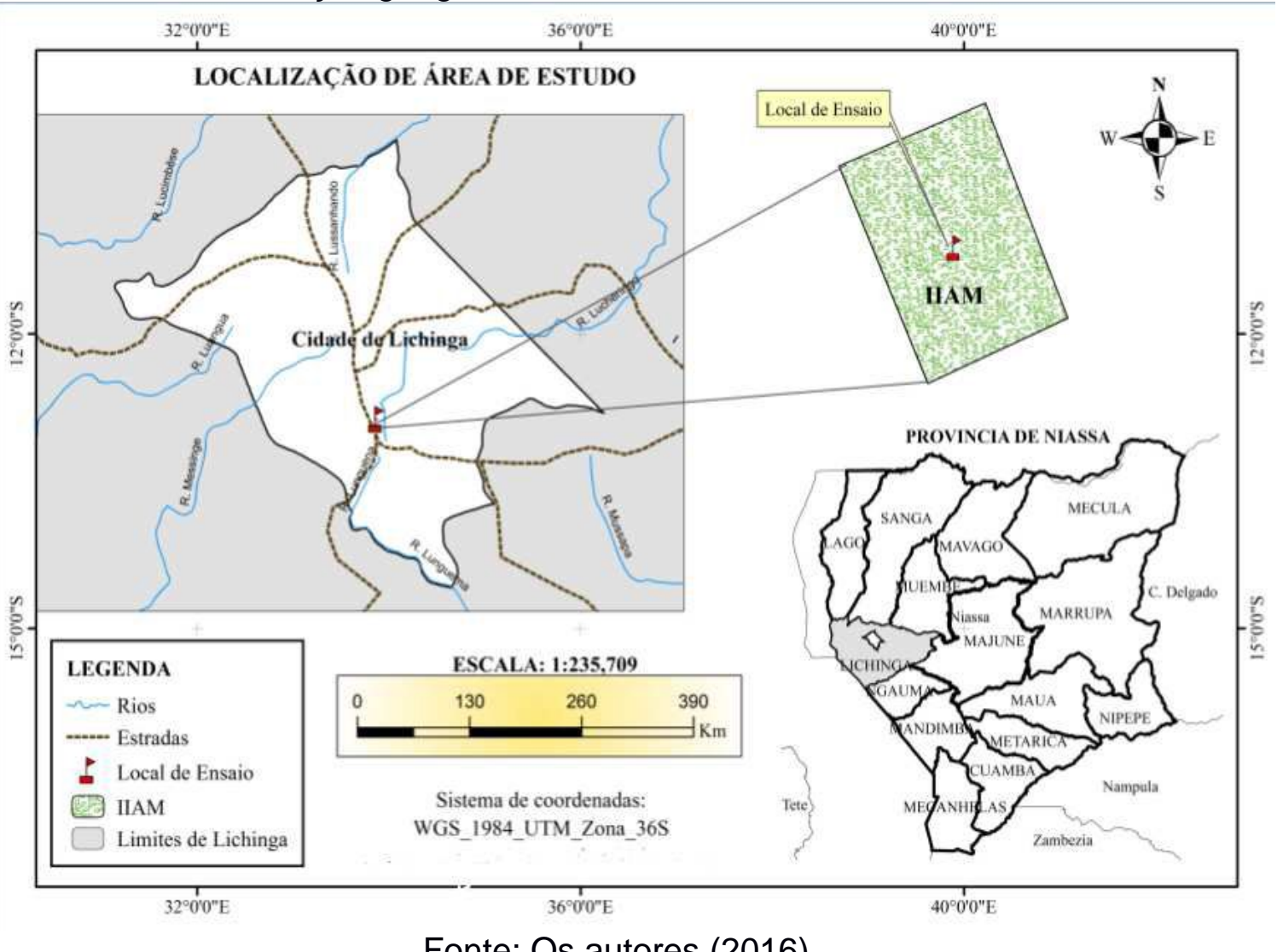

Fonte: Os autores (2016) 


\section{Estabelecimento do experimento}

O experimento foi conduzido seguindo o delineamento de blocos completamente casualizados (DBCC) com 15 tratamentos e quatro repetições, sendo os tratamentos constituídos por 14 genótipos de feijão vulgar provenientes do programa de melhoramento do Centro Internacional de Agricultura Tropical (CIAT) da Zâmbia e uma variedade local proveniente do Instituto de Investigação Agrária de Moçambique - IIAM que foi usada como testemunha (Quadro 1). A unidade experimental foi composta de quatro linhas de 3,0 $\mathrm{m}$ de comprimento e 2,0 $\mathrm{m}$ de largura, espaçadas $0,5 \mathrm{~m}$ entre linhas e 0,2 $\mathrm{m}$ entre plantas, com a área útil da parcela correspondendo às duas linhas centrais $\left(3 \mathrm{~m}^{2}\right)$. Foram usadas 108 sementes para cada genótipo.

QUADRO 1. Lista dos genótipos de feijão vulgar utilizados no experimento.

\begin{tabular}{cccccc}
\hline Tratamento & Genótipo & Origem & Tratamento & Genótipo & Origem \\
\hline 1 & SAB793 & CIAT & 9 & DAB449 & CIAT \\
2 & ALB105 & CIAT & 10 & DAB433 & CIAT \\
3 & DAB210 & CIAT & 11 & ALB117 & CIAT \\
4 & KG17-23 & CIAT & 12 & NAE13 & CIAT \\
5 & SMC32 & CIAT & 13 & NAE87 & CIAT \\
6 & NAE24 & CIAT & 14 & CAL143 & CIAT \\
7 & Testemunha & IIAM & 15 & ALB1 & CIAT \\
8 & BF13607-9 & CIAT & & & \\
\hline
\end{tabular}

A preparação do solo foi mecanizada, tendo sido utilizada uma charrua de disco a uma profundidade de $20 \mathrm{~cm}$ e uma grade niveladora. A sementeira foi manual (uma semente por covacho na profundidade de $2,0 \mathrm{~cm}$ ) precedida de uma adubação de fundo/base com NPK com proporção 12-24-12. Durante a condução do ensaio foi realizada uma pulverização curativa para minimizar o índice de ataque da mosca e do afídeo e duas capinas para eliminar infestantes, promover o arejamento e um bom desenvolvimento das plantas.

\section{Coleta e análise de dados}

Antes da colheita foram coletadas as variáveis hábito de crescimento: determinada através da observação das plantas, sendo consideradas plantas com hábito determinado aquelas cujas hastes principais e laterais terminavam com a formação de uma inflorescência que teria paralisado o seu crescimento; doenças foliares (ferrugem nas folhas e mancha angular nas folhas): por meio de observação seguida da definição do nível de ataque utilizando-se a escala de avaliação de James (1971), logo após o início da fase reprodutiva; altura das plantas: obtida através da altura média de 10 plantas selecionadas aleatoriamente, no período da maturação, após cessar o crescimento; estande inicial/Número de plantas emergentes: através da contagem de plantas emergidas após germinação de mais de $50 \%$ em todas parcelas; e floração: o 
número de dias desde a emergência até ao estágio em que $50 \%$ das plantas da parcela estiverem em floração.

No período da colheita, 100 dias após da sementeira, foram coletadas as seguintes variáveis por parcela: estande final/número de plantas colhidas, número de vagens por planta, comprimento de vagens, número de sementes por vagens, peso das vagens, peso de 100 sementes e produtividade de grãos.

Os dados obtidos foram submetidos aos testes de Shapiro-Wilk e Breusch-Pagan para testar a normalidade e a homoscedasticidade, respectivamente, utilizando-se o programa SISVAR V 5.0. Após, foram realizadas as análises de variância e as comparações das médias pelo teste de Tukey.

\section{RESULTADOS}

Não houveram diferenças significativas entre os tratamentos $(p>0,05)$ para 0 número de plantas emergidas (estande inicial), com uma média de 43,79. Entretanto, houve diferença $(p<0,05)$ para $o$ número de plantas colhidas (estande final), tendo a variedade local e os genótipos SAB793, ALB105, BF13607-9, ALB117, CAL143 e ALB1 se destacado sobre os demais (Tabela 1).

No que diz respeito ao hábito de crescimento, houve predominância do tipo determinado (I), com uma frequência de $86,6 \%$. Apenas os genótipos NAE24 e DAB449 apresentaram hábito de crescimento do tipo indeterminado (II). Moçambique (2010) afirma que o feijoeiro comum apresenta os hábitos de crescimento determinado (tipo I), cuja característica principal é a floração que inicia do ápice para a base da planta, e indeterminado (tipo II), em que a planta apresenta um crescimento continuo, sucessão de nós e entrenós, inflorescências desenvolvidas nas axilas das folhas e floração iniciando da base para o ápice da planta (Tabela 1).

Houve também registro de ocorrência de duas doenças, nomeadamente a mancha angular e a ferrugem. $O$ índice de incidência de ataque da mancha angular variou entre 0 e 10\%, com destaque para os genótipos SMC32 e CAL143 que não foram atacados, enquanto os índices ataque de ferrugem variaram de 0 a $19,17 \%$ e os genótipos DAB210, KG17-23 e NAE24 não sofreram ataque (Tabela 1 ).

Houveram diferenças significativas entre os genótipos em termos de altura de plantas, sendo o genótipo DAB449 se destacado com uma altura de 42,0 cm. As menores alturas foram observadas nos genótipos KG17-23, ALB105 e BF13607-9. Houve também diferenças significativas para a variável floração, em que o genótipo BF13607-9 se destacou, tendo levado menos dias para florir (33 dias), porém, sem diferença significativa sobre os demais genótipos, com exceção dos genótipos DAB210, NAE24 e DAB449. 
TABELA 1. Médias dos parâmetros de crescimento dos genótipos de feijão vulgar. Sobrevivência - Número de plantas emergentes (NPE), Estande final (NPC); Hábito de crescimento (HACRE); Altura da planta (AP); Floração (FLOR); Resistência a doenças Mancha angular nas folhas (ALS), Ferrugem nas folhas (RUSTEL).

\begin{tabular}{|c|c|c|c|c|c|c|c|}
\hline $\begin{array}{l}\text { Tratamen } \\
\text { to }\end{array}$ & NPE & NPC & HACRE & $\begin{array}{l}\mathrm{AP} \\
(\mathrm{cm})\end{array}$ & $\begin{array}{l}\text { FLOR } \\
\text { (dias) }\end{array}$ & $\begin{array}{l}\text { ALS } \\
(\%)\end{array}$ & $\begin{array}{c}\text { RUSTEL } \\
(\%)\end{array}$ \\
\hline SAB793 & $\begin{array}{c}46,7 \\
5\end{array}$ & $\begin{array}{c}43,75 \\
b\end{array}$ & I & $\begin{array}{c}26,25 \\
a b\end{array}$ & $35,00 a b$ & 6,74 & 0,43 \\
\hline ALB105 & $\begin{array}{c}49,5 \\
0\end{array}$ & $\begin{array}{c}46,00 \\
b\end{array}$ & I & $\begin{array}{c}24,30 \\
a\end{array}$ & $44,00 \mathrm{c}$ & 1,39 & 2,98 \\
\hline DAB210 & $\begin{array}{c}42,2 \\
5\end{array}$ & $\begin{array}{c}37,00 \\
a b\end{array}$ & I & $\begin{array}{c}29,85 \\
a b\end{array}$ & $37,5 \mathrm{abc}$ & 8,79 & 0,00 \\
\hline KG17-23 & $\begin{array}{c}38,5 \\
0\end{array}$ & $\begin{array}{c}32,00 \\
a\end{array}$ & I & $\begin{array}{c}22,97 \\
a\end{array}$ & $\begin{array}{c}38,25 \\
a b c\end{array}$ & 3,61 & 0,00 \\
\hline SMC32 & $\begin{array}{c}42,5 \\
0\end{array}$ & $\begin{array}{c}32,75 \\
a\end{array}$ & I & $\begin{array}{c}32,10 \\
a b\end{array}$ & $34,25 a b$ & 0,00 & 19,17 \\
\hline NAE24 & $\begin{array}{c}39,0 \\
0\end{array}$ & $\begin{array}{c}31,75 \\
a\end{array}$ & II & $\begin{array}{c}37,72 \\
a b\end{array}$ & $41,00 \mathrm{bc}$ & 10,0 & 0,00 \\
\hline $\begin{array}{l}\text { Testemun } \\
\text { ha }\end{array}$ & $\begin{array}{c}46,2 \\
5\end{array}$ & $\begin{array}{c}42,00 \\
b\end{array}$ & I & $\begin{array}{c}29,72 \\
a b\end{array}$ & $\begin{array}{c}37,00 \\
a b c\end{array}$ & 7,74 & 0,58 \\
\hline $\begin{array}{l}\text { BF13607- } \\
9\end{array}$ & $\begin{array}{c}50,2 \\
5 \\
\end{array}$ & $\begin{array}{c}49,25 \\
b\end{array}$ & I & $\begin{array}{c}24,32 \\
a \\
\end{array}$ & $33,00 \mathrm{a}$ & 0,53 & 3,02 \\
\hline DAB449 & $\begin{array}{c}44,0 \\
0\end{array}$ & $\begin{array}{c}37,75 \\
a b\end{array}$ & II & $\begin{array}{c}42,00 \\
b\end{array}$ & $41,25 \mathrm{bc}$ & 5,40 & 1,25 \\
\hline DAB433 & $\begin{array}{c}38,7 \\
5\end{array}$ & $\begin{array}{c}32,00 \\
a\end{array}$ & I & $\begin{array}{c}26,02 \\
a b\end{array}$ & $\begin{array}{c}38,00 \\
a b c\end{array}$ & 3,43 & 12,20 \\
\hline ALB117 & $\begin{array}{c}46,2 \\
5\end{array}$ & $\begin{array}{c}42,50 \\
b\end{array}$ & I & $\begin{array}{c}28,55 \\
a b\end{array}$ & $\begin{array}{c}40,75 \\
a b c\end{array}$ & 1,60 & 1,90 \\
\hline NAE13 & $\begin{array}{c}41,0 \\
0\end{array}$ & $\begin{array}{c}35,50 \\
a b\end{array}$ & I & $\begin{array}{c}28,42 \\
a b\end{array}$ & $\begin{array}{c}36,75 \\
a b c\end{array}$ & 9,24 & 9,96 \\
\hline NAE87 & $\begin{array}{c}37,2 \\
5\end{array}$ & $\begin{array}{c}31,25 \\
a\end{array}$ & I & $\begin{array}{c}27,15 \\
a b\end{array}$ & $37,5 \mathrm{abc}$ & 3,13 & 5,14 \\
\hline CAL143 & $\begin{array}{c}47,5 \\
0\end{array}$ & $\begin{array}{c}43,00 \\
b\end{array}$ & I & $\begin{array}{c}36,17 \\
a b\end{array}$ & $\begin{array}{c}36,75 \\
a b c\end{array}$ & 0,00 & 1,11 \\
\hline ALB1 & $\begin{array}{c}46,7 \\
5 \\
\end{array}$ & $\begin{array}{c}42,25 \\
b\end{array}$ & I & $\begin{array}{c}32,5 \\
a b\end{array}$ & $\begin{array}{c}39,25 \\
a b c\end{array}$ & 0,78 & 6,57 \\
\hline Valor- $P$ & $\begin{array}{l}0,17 \\
93 \mathrm{~ns}\end{array}$ & $\underset{*}{0,0396}$ & - & $\begin{array}{c}0,0071 \\
*\end{array}$ & $0,0009^{*}$ & - & - \\
\hline Média & $\begin{array}{c}43,7 \\
6\end{array}$ & 38,58 & - & 29,87 & 38,01 & - & - \\
\hline CV (\%) & $\begin{array}{c}16,0 \\
7\end{array}$ & 21,54 & - & 22,16 & 8,19 & & \\
\hline
\end{tabular}

${ }^{*}$ Significativo pelo teste $\mathrm{F}$ a $5 \%(\mathrm{P}<0,05)$; ns não significativo pelo teste $\mathrm{F}$ a $5 \%$ $(P \geq 0,05)$. Médias seguidas pela mesma letra na coluna não diferem entre si pelo teste Tukey a $5 \%$ de significância. 
Em relação aos parâmetros de rendimento, não houveram diferenças significativas entre os genótipos para o número de vagens por planta (média 8,73), número de sementes/vagem (média 4,56), peso das vagens (média 0,41 g) e produtividade (média $911,66 \mathrm{~kg} / \mathrm{ha}$ ). Contudo, houve efeito significativo dos tratamentos sobre o comprimento da vagem e o peso de 100 sementes. A variedade local e os genótipos SCM32, DAB433, NAE13, NAE87 e ALB1 obtiveram os maiores comprimentos de vagem, contudo, sem diferença estatística com os demais, com a exceção do DAB210. Já os genótipos ALB117, NAE13 e NAE87 tiveram os maiores pesos de 100 sementes, mas sem diferença estatística com SAB793, NAE24, BF13607, DAB449, DAB433, CAL143 e ALB1 (Tabela 2).

TABELA 2. Médias dos parâmetros de rendimento dos genótipos de feijão vulgar. Número de Vagens por planta (NVP); Comprimento da Vagem (CompV), Número de Sementes Por Vagem (NSV); Peso das Vagens (PV); Peso de 100 Sementes (P100S); Produtividade (PROD).

\begin{tabular}{lcccccc}
\hline \multicolumn{1}{c}{ Tratamento } & NVP & $\begin{array}{c}\text { CompV } \\
(\mathrm{cm})\end{array}$ & NSV & PV(kg) & P100S & $\begin{array}{c}\text { PROD } \\
(\mathrm{kg} / \mathrm{ha})\end{array}$ \\
\hline SAB793 & 8,25 & $10.77 \mathrm{ab}$ & 4.00 & 0.30 & $0,042 \mathrm{abc}$ & 712,5 \\
\hline ALB105 & 6,75 & $10.77 \mathrm{ab}$ & 5.00 & 0.43 & $0,025 \mathrm{de}$ & 987,5 \\
\hline DAB210 & 13,25 & $9.15 \mathrm{~b}$ & 4.75 & 0.47 & $0,022 \mathrm{e}$ & 1150 \\
\hline KG17-23 & 12,0 & $9.82 \mathrm{ab}$ & 4.75 & 0.37 & $0,02 \mathrm{e}$ & 908,33 \\
\hline SMC32 & 7,50 & $11.92 \mathrm{a}$ & 4.50 & 0.34 & $0,04 \mathrm{abcd}$ & 704,16 \\
\hline NAE24 & 12,5 & $10.72 \mathrm{ab}$ & 5.50 & 0.44 & $0,03 \mathrm{bcde}$ & 966,66 \\
\hline Testemunha & 6,75 & $11.35 \mathrm{a}$ & 3.75 & 0.38 & $0,045 \mathrm{ab}$ & 787,49 \\
\hline BF13607-9 & 7,50 & $11.30 \mathrm{ab}$ & 4.75 & 0.41 & $\begin{array}{l}0,035 \\
\mathrm{abcde}\end{array}$ & 866,66 \\
\hline DAB449 & 8,50 & $10.85 \mathrm{ab}$ & 5.50 & 0.38 & $0,027 \mathrm{cde}$ & 808,33 \\
\hline DAB433 & 6,75 & $11.52 \mathrm{a}$ & 4.50 & 0.31 & $0,045 \mathrm{ab}$ & 633,33 \\
\hline ALB117 & 6,25 & $11.15 \mathrm{ab}$ & 4.00 & 0.52 & $0,05 \mathrm{a}$ & 1183,33 \\
\hline NAE13 & 8,00 & $11.60 \mathrm{a}$ & 4.25 & 0.34 & $0,05 \mathrm{a}$ & 716,66 \\
\hline NAE87 & 8,00 & $11.92 \mathrm{a}$ & 4.50 & 0.48 & $0,047 \mathrm{a}$ & 1175 \\
\hline CAL143 & 10,25 & $11.12 \mathrm{ab}$ & 4.50 & 0.52 & $0,045 \mathrm{ab}$ & 1162,5 \\
\hline ALB1 & 8,75 & $11.42 \mathrm{a}$ & 4.25 & 0.42 & $0,042 \mathrm{abc}$ & 912,5 \\
\hline Valor- $P$ & $0,0558 \mathrm{~ns}$ & $0.0024^{*}$ & $0.0900 \mathrm{n}$ & $0.4887 \mathrm{n}$ & $0.0001^{*}$ & $0.2080 \mathrm{n}$ \\
\hline Média & 8.73 & 11,02 & 4.56 & 0.41 & 0.037 & 911.66 \\
\hline CV (\%) & 37,2 & 7,69 & 16.88 & 33.95 & 16,33 & 35,29 \\
\hline
\end{tabular}

${ }^{*}$ Significativo pelo teste $\mathrm{F}$ a $5 \%(\mathrm{P}<0.05)$; ns não significativo pelo teste $\mathrm{F}$ a $5 \%$ $(P \geq 0.05)$. Médias seguidas pela mesma letra na coluna não diferem entre si pelo teste Tukey a 5\% de significância.

\section{DISCUSSÃO}

O experimento teve diferentes níveis de precisão em função da variável. Os coeficientes de variação foram classificados, segundo Garcia (1989), em: baixo, para floração e comprimento das vagens, revelando ótima precisão; 
médio, para número de plantas emergidas/stand inicial, número de sementes por vagens e peso de 100 sementes, com média dispersão de dados; alto, para número de plantas colhidas/stand final e altura das plantas, com precisão regular; e muito alto para o número de vagens planta, peso das vagens e produtividade, indicativo de baixa precisão.

Foi observado que a maior parte dos genótipos teve sobrevivência semelhante à variedade local, o que indica a possibilidade do uso desses genótipos em programas de melhoramento genético para melhorar outras características como a produtividade. Entretanto, a maioria dos genótipos se mostrou suscetível ao ataque das doenças registradas na área, o que deverá ser um fator a considerar na produção dessa cultura, pois Fiallos (2010) afirma que 0 ataque de doenças pode causar grandes prejuízos financeiros aos produtores do feijão vulgar. No nosso estudo nenhum genótipo foi resistente ao ataque de ambas as doenças. A mancha angular foi registrada também por outros autores (ZEVO, 2013; PAULINO, 2015) no planalto de Lichinga.

Os valores da altura e do número de dias para floração são similares aos encontrados por Mcuinda (2016), que variaram entre 32,5 e $45,25 \mathrm{~cm}$. Moçambique (2010) obteve o menor período de 42 dias, ao passo que Zevo (2013) obteve valores entre 33 a 40,25 dias,

Relativamente aos parâmetros de rendimento, resultados similares também foram obtidos em outros estudos com feijão vulgar. Santos e Lima (2015) obtiveram de 6,13 a 12,75 vagens/planta ao passo que Zevo (2013) obteve 6,25 a 19,75. Por seu turno, Santos e Lima (2015) obtiveram de 4,43 a 5, 5,9 sementes por vagem. Em relação ao comprimento da vagem e o peso de 100 sementes, cujas médias entre tratamentos foram diferentes, os valores obtidos são idênticos aos obtidos por Moçambique (2010) que relatou valores de comprimento da vagem de 8,22 a $10,71 \mathrm{~cm}$ e o peso de 100 sementes variou de 18,94 a 25,28 g.

Para a maioria dos parâmetros estudados não houve diferença estatística entre os tratamentos. Entretanto, o genótipo DAB449 se destacou no crescimento em altura, o genótipo BF13607-9 na floração, os genótipos SCM 32 , DAB 433, NAE13, NAE87, ALB 1 e a testemunha, no comprimento de vagem, enquanto os genótipos ALB117, NAE13 e NAE87 tiveram os maiores pesos de 100 sementes. Embora esses genótipos não sejam estatisticamente superiores a outros, podem ser usados como referência na produção de feijão vulgar no planalto de Lichinga em função das características que se deseja melhorar. Para o caso de rendimento, o genótipo NAE87 é o mais indicado, pois produz vagem mais comprida e maior peso de grão.

\section{CONCLUSÃO}

Os genótipos avaliados tiveram ligeiras diferenças entre si, além de terem sido suscetíveis ao ataque de doenças. Ainda assim, os genótipos BF13607-9 e NAE87 são os mais indicados para o planalto de Lichinga por terem se destacado nos parâmetros de crescimento (floração) e de rendimento (comprimento de vagem e peso de 100 sementes), respectivamente. Entretanto, esses genótipos podem ser substituídos por outros cujas diferenças não foram significativas. 


\section{REFERÊNCIAS}

CIPRIANO, S.; SILVA, J. Relação entre o rendimento de grão do milho (zea mays I.), nitrogénio e fósforo aplicados no solo. Revista Electrónica de Investigação e Desenvolvimento, v.2, n.8, 2017.

FIALLOS, F.R.G. Doenças causadas por vírus na cultura de feijoeiro (Phaseolus vulgaris I.). Científica y Tecnología, v.3, n.2, p: 1-6, 2010.

GARCIA, C.H. Tabelas para classificação do coeficiente de variação. Piracicaba: IPEF, 1989. 12p (Circular Técnica, 171, Brasil, 1989.

GOUVEIA, C.S.S. Avaliação de Recursos Genéticos Agrícolas: Análise nutricional e anti-nutricional de variedades regionais de feijão (Phaseolus vulgaris L.). 2011. 107f. Dissertação (Mestrado em Bioquímica Aplicada) Universidade de Madeira, Madeira, 2011.

INE - Instituto Nacional de estatística. Censo Agro-pecuário 2009-2010. Maputo: INE, 2011.

INE - Instituto Nacional de estatística. Estatísticas do distrito de cidade de Lichinga. Maputo: INE, 2013.

JAMES, W.C. Assessment of plant disease and losses. Annual Review Phytopathology, v.12, p.27-48, 1974.

JOCHUA, C.N.; STEADMAN, J.R.; AMANE, M.; FENTON, J.G. Pathotype variation and sources of resistance to the common bean rust pathogen in Southern Mozambique. Annual Report of the Bean Improvement Cooperative, v.47, p.113-114, 2004.

MCUINDA, M.E. Avaliação da produção de milho e leguminosas (soja, feijão vulgar e boer) em sistema de consociação, nas condições agro-geológicas do planalto de Lichinga. 2016. Monografia (Licenciatura em Engenharia de Desenvolvimento Rural) - Universidade Lúrio, Unango, Moçambique, 2016.

MOÇAMBIQUE, P.A. Caracterização fenotípica de acessos crioulos de Phaseolus vulgaris $\mathrm{L}$. do tipo carioca baseada em análise multivariada. 2010. 101f. Tese (Doutorado em Agronomia) - Universidade Federal de Goiás, Goiânia, 2010.

PAULINO, M.C.J. (2015). Avaliação do comportamento de 20 variedades de feijão vulgar (Phaseolus vulgaris L.) nas condições agro-ecológicas do planalto de Lichinga. 2016. Monografia (Licenciatura em Engenharia de Desenvolvimento Rural) - Universidade Lúrio, Unango, Moçambique, 2016.

SANTOS, F.A.S., LIMA, A.R. Características produtivas de diferentes cultivares 
de feijão (Phaseolus vulgaris L.) no município de Cáceres-MT, Enciclopédia Biosfera, Centro Científico Conhecer, v.11 n.21, p.408-420, 2015.

SILVA, V.P.; CASIMIRO, E.L.N.; LAZARETTI, N.S. Avaliação de perdas de grãos e qualidade fisiológica na colheita mecanizada do feijão. Revista Cultivando o Saber, Ed. especial, p.32-43, 2018.

ZEVO, I. Avaliação do comportamento de 16 genótipos de Feijão vulgar (Phaseolus vulgaris L.) nas condições agro-ecológicas do planalto de Lichinga. 2013. Monografia (Licenciatura em Engenharia de Desenvolvimento Rural) - Universidade Lúrio, Unango, Moçambique, 2013. 